\title{
DISTRIBUSI FREKUENSI IBU PASCAMELAHIRKAN DENGAN KEJADIAN BABY BLUES SYNDROME DI PRAKTIK MANDIRI BIDAN WILAYAH KECAMATAN RAJABASA BANDAR LAMPUNG TAHUN 2019
}

\author{
Fonda Octarianingsih ${ }^{1}$, Festy Ladyani ${ }^{2}$, Woro Pramesti ${ }^{3}$, Nadya Putri Amany ${ }^{4}$ \\ ${ }^{1}$ Departemen Obstetri \& Ginekologi Fakultas Kedokteran Universitas Malahayati \\ ${ }^{2}$ Departemen Gizi Medik Fakultas Kedokteran Universitas Malahayati \\ ${ }^{3}$ Departemen Ilmu Kesehatan Jiwa Fakultas Kedokteran Universitas Malahayati \\ ${ }^{4}$ Program Studi Kedokteran Fakultas Kedokteran Universitas Malahayati
}

[email korespondensi: putrinadya553@gmail.com]

\begin{abstract}
Frequency Distribution Of Postpartum Maternal With Baby Blues Syndrome Incident In Praktik Mandiri Bidan Sub District Rajabasa Bandar Lampung In 2019. In women pregnant and gave birth events had happened in his life is considered normal. However, changes in childbirth can not be passed by the majority of women so that women can not adapt to the conditions. One of the changes is felt every woman is postpartum emotional changes. Emotional disturbance will occur is uncertain, at least the mother felt two emotions that positive emotions (joy and satisfaction) and negative emotions (fear and anxiety) if the mother does not adapt to the situation, the mother may experience baby blues syndrome. Baby blues syndrome is a form of interference maternal feelings because they can not adapt to their babies. Measuring instrument used was a questionnaire EPDS (Edinburgh Postpartum Depression Scale).The purpose of this study to determine the frequency distribution of postpartum maternal with baby blues syndrome incident in Praktik Mandiri Bidan Sub District Rajabasa Bandar Lampung in 2019. This research using quantitative descriptive method with primary data to determine the distribution of postpartum maternal with baby blues syndrome incident. The study sample as many as 77 postpartum maternal that taken with total sampling technique which is housed in Praktik Mandiri Bidan Sub District Rajabasa Bandar Lampung. Data analysis used univariate statistical analysis of the frequency distribution of SPSS 20.The results of this study were obtained did not the incidence of baby blues syndrome as much as 54 postpartum maternal $(70.1 \%)$ and the incidence of baby blues syndome as much as 23 postpartum maternal $(29,9 \%)$. Obtained frequency distribution of postpartum maternal with baby blues incident in Praktik Mandiri Bidan Sub District Rajabasa Bandar Lampung in 2019.
\end{abstract}

Keywords: Postpartum Maternal, Baby Blues Syndrome

Abstrak: Distribusi Frekuensi Ibu Pascamelahirkan Dengan Kejadian Baby
Blues Syndrome Di Praktik Mandiri Bidan Wilayah Kecamatan Rajabasa
Bandar Lampung Tahun 2019. Pada wanita peristiwa hamil dan melahirkan
sudah dianggap wajar terjadi di kehidupannya. Namun perubahan pada saat
melahirkan tidak dapat dilalui oleh sebagian besar wanita sehingga wanita tidak
bisa beradaptasi dengan kondisinya.Salah satu perubahan yang dirasakan setiap
wanita pascamelahirkan adalah perubahan emosional. Gangguan emosional akan
terjadi tidak menentu, setidaknya ibu merasakan dua emosi yaitu emosi positif
(suka cita dan kepuasan) dan emosi negatif (ketakutan dan kecemasan) apabila ibu
tidak beradaptasi dengan kondisinya, ibu bisa mengalami baby blues syndrome.
Baby blues syndrome merupakan salah satu bentuk gangguan perasaan ibu karena
tidak bisa beradaptasi dengan bayinya. Alat ukur yang digunakan adalah kuesioner
EPDS (Edinburgh Postpartum Depression Scale). Tujuan penelitian ini untuk 
mengetahui distribusi frekuensi ibu pascamelahirkan dengan kejadian baby blues syndrome di Praktik Mandiri Bidan Wilayah Kecamatan Rajabasa Bandar Lampung Tahun 2019. Penelitian ini menggunakan metode deskriptif kuantitatif dengan data primer untuk mengetahui distribusi ibu pascamelahirkan dengan kejadian baby blues syndrome. Sampel penelitian ini sebanyak 77 ibu pascamelahirkan yang diambil dengan teknik total sampling yang bertempat di Praktik Mandiri Bidan Kecamatan Rajabasa Bandar Lampung.Analisis data menggunakan uji statistika analisis univariat distribusi frekuensi SPSS 20. Hasil dari penelitian ini didapatkan sebanyak 54 ibu pascamelahirkan $(70,1 \%)$ tidak mengalami kejadian baby blues syndrome dan sebanyak 23 ibu pascamelahirkan (29,9\%) dengan kejadian baby blues syndrome.Didapatkan distribusi frekuensi ibu pascamelahirkan dengan kejadian baby blues syndrome di Praktik Mandiri Bidan Wilayah Kecamatan Rajabasa Bandar Lampung Tahun 2019.

Kata Kunci : Ibu pascamelahirkan, Baby Blues Syndrome

\section{PENDAHULUAN}

Proses adaptasi psikologis akan terjadi saat dinyatakan ibu mulai hamil.Setidaknya ada dua emosi yang dialami ibu hamil yaitu emosi positif (sukacita dan kepuasan) dan emosi negatif (ketakutan dan kecemasan). Menurut Jhaquin (2010) menjalani adaptasi psikologis setelah melahirkan ibu akan mengalami fasefase berikut ini :Fasetaking in yaitu periode ketergantungan yang berlangsung pada hari pertama sampai hari kedua setelah melahirkan. Pada saat itu fokus perhatian ibu terutama pada diri sendiri.Pangalaman sering berulang diceritakannya hal ini membuat ibu cenderung menjadi pasif terhadap lingkungan.Fase taking hold yaitu periode yang berlangsung antara 3-10 hari setelah melahirkan. Pada fase ini ibu merasa khawatir akan ketidakmampuannya dan rasa tanggung jawabnya dalam merawat bayi. Pada fase ini ibu memerlukan dukungan dan merupakan kesempatan yang baik menerima berbagai penyuluhan dalam merawat diri dan bayinya sehingga timbul percaya diri.Fase letting go merupakan fase menerima tanggung jawab akan peran barunya yang berlangsung sepuluh hari setelah melahirkan. Ibu sudah dapat menyesuaikan diri, merawat diri dan bayinya sudah meningkat. Ada kalanya ibu mengalami perasaan sedih yang berkaitan dengan bayinya keadaan ini disebut baby blues.

Adaptasi pascamelahirkan tidak dapat dilalui oleh semua ibu, kenyataannya bahwa sebagian ibu tidak dapat beradaptasi dengan kondisinya.Ibu yang melahirkan seringkali mengalami perasaan sedih mengenai bayinya (baby blues) yang disebabkan oleh perubahan perasaan yang dialami saat hamil sehingga sulit menerima kehadiran bayinya (Suryani dan Widyaningsih, 2010).

Berdasarkan hasil presurvei yang dilakukan peneliti, kecamatan Rajabasa memiliki jumlah penduduk 51.578 jiwa dengan jumlah laki-laki 26.237 jiwa dan perempuan 25.341 jiwa. Kecamatan Rajabasa pada tahun 2018 menunjukkan tingginya angka kejadian ibu pascamelahirkan yaitu berjumlah 932 orang.

Pelaporan prevalensi kejadian baby blues syndrome bervariasi diseluruh dunia. Angka kejadian baby blues syndrome di Asia berkisaran $3.5 \%$ hingga $63,3 \%$ dimana Malaysia dan Pakistan menjadi peringkat yang terendah dan tertinggi (Klainin \& Arthur, 2009). Angka kejadian baby blues syndrome di Indonesia antara $50 \%$ hingga $70 \%$ (Munawaroh, 2008).

Postpartum Distress Syndrome atau yang juga disebut dengan Baby Blues Syndrome merupakan reaksi psikologi yang berupa gejala depresi postpartum dengan tingkat ringan. Keadaan ini akan terjadi dalam 
beberapa hari saja setelah melahirkan dan biasanya akan berangsur-angsur menghilang dalam beberapa hari dan masih dianggap sebagai suatu kondisi yang normal terkait dengan adaptasi psikologis postpartum. Apabila memiliki faktor predisposisi dan pemicu lainnya maka dapat berlanjut menjadi depresi postpartum (Pilliteri, 2003; Lynn dan Pierre, 2007 dalam Macmudah, 2010).

Jika kondisi baby blues syndrome tidak disikapi dengan benar, bisa berdampak pada hubungan ibu dengan bayinya, bahkan anggota keluarganya yang lain juga bisa merasakan dampak dari baby blues syndrome tersebut.

Apabila gangguan psikiatrik diatas tidak bisa tertangani dengan baik, maka dapat menimbulkan gangguan mental berat yang dimana memerlukan perawatan serius karena perempuan tersebut dapat melukai dirinya ataupun bayinya, kondisi tersebut dinamakan postpartum psychosis.

\section{METODE}

Penelitian ini dilakukan di Praktik Mandiri Bidan Wilayah
Kecamatan Rajabasa Bandar Lampung. Dengan tujuan untuk mengetahui jumlah distribusi frekuensi ibu pascamelahirkan dengan kejadian baby blues syndrome. Jenis penelitian ini adalah deskriptif kuantitatif dengan menggunakan data primer (kuesioner) dan teknik total sampling, dimana terdapat kriteria inklusi dan ekslusi. Kriteria insklusi dalam penelitian ini adalah ibu pascamelahirkan 7-14 hari, ibu dengan kejadian baby blues syndrome, ibu yang bersedia menjadi responden, dan ibu yang bisa membaca tulisan. Sedangkan kriteria eksklusi dari penelitian ini adalah ibu yang tidak dapat membaca tulisan, ibu dengan riwayat gangguan jiwa, dan kondisi ibu sangat lemah dan mengalami gangguan kesadaran. Data sampel dari penelitian ini adalah ibu pascamelahirkan yang terdaftar di Praktik Mandiri Bidan Wilayah Kecamatan Rajabasa serta masuk dalam kriteria inklusi yaitu sebanyak 77 sampel ibu pascamelahirkan.Penelitian ini dilaksanakan pada bulan November sampai Desember tahun2019.

HASIL

Data gambaran subjek penelitian dapat dilihat pada tabel di bawah ini.

Tabel 1. Distribusi Frekuensi Kejadian Baby Blues Syndrome

\begin{tabular}{ccc}
\hline Kejadian & Jumlah & Presentase (\%) \\
\hline Normal & 54 & 70,1 \\
Baby Blues Syndrome & 23 & 29,9 \\
\hline Total & $\mathbf{7 7}$ & $\mathbf{1 0 0}$ \\
\hline
\end{tabular}

Berdasarkan tabel 1 diatas menunjukkan bahwa distribusi frekuensi ibu pascamelahirkandi Praktik Mandiri Bidan Wilayah Kecamatan Rajabasa Bandar Lampung Tahun 2019 berjumlah
77. Responden didapatkan 54 ibu pascamelahirkan $(70,1 \%)$ normal dan 23 ibu pascamelahirkan (29,9\%) dengan kejadian baby blues syndrome. 
Tabel 2. Distribusi Frekuensi Kejadian Baby Blues Syndrome Berdasarkan Usia

\begin{tabular}{ccccc}
\hline Usia & Normal & $\begin{array}{c}\text { Baby Blues } \\
\text { Syndrome }\end{array}$ & Jumlah & Presentase (\%) \\
\hline $21-$ 35 Tahun & 42 & 17 & 59 & 76,6 \\
$\leq 20$ dan $>35$ & 12 & 6 & 18 & 23,4 \\
\hline Tahun & $\mathbf{5 4}$ & $\mathbf{2 3}$ & $\mathbf{7 7}$ & $\mathbf{1 0 0}$ \\
\hline Total & & & &
\end{tabular}

Berdasarkantabel 2 diatas menunjukkan bahwa didapatkan sebanyak 59 ibu pascamelahirkan
$(76,6 \%)$ dengan usia 21 - 35 tahun dan 18 ibu pascamelahirkan $(23,4 \%)$ dengan usia $\leq 20$ dan $>35$ tahun.

Tabel 3. Distribusi Frekuensi Kejadian Baby Blues Syndrome Berdasarkan Paritas

\begin{tabular}{ccccc}
\hline Paritas & Normal & $\begin{array}{c}\text { Baby Blues } \\
\text { Syndrome }\end{array}$ & Jumlah & $\begin{array}{c}\text { Presentase } \\
(\%)\end{array}$ \\
\hline Primipara & 18 & 10 & 28 & 36,4 \\
Multipara & 36 & 13 & 49 & 63,6 \\
\hline Total & $\mathbf{5 4}$ & $\mathbf{2 3}$ & $\mathbf{7 7}$ & $\mathbf{1 0 0}$ \\
\hline
\end{tabular}

Berdasarkan tabel 3 diatas menunjukkan bahwa didapatkan sebanyak sebanyak 28 ibu pascamelahirkan $(36,4 \%)$ dengan kategori primipara dan 49 ibu pascamelahirkan $(63,6 \%)$ dengan kategori multipara.

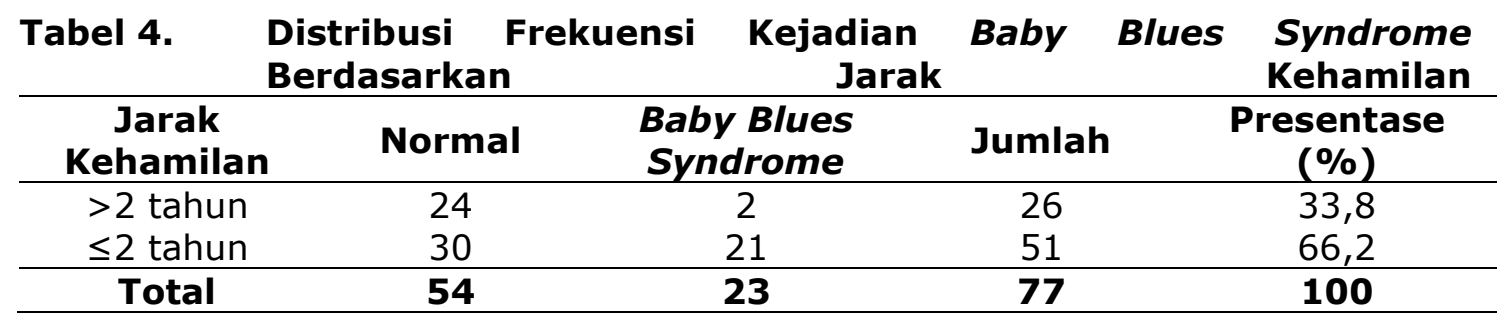

Berdasarkan tabel 4 diatas menunjukkan bahwa didapatkan sebanyak 26 ibu pascamelahirkan $(33,8 \%)$ dengan jarak kehamilan $<2$ tahun dan 51 ibu pascamelahirkan $(66,2 \%)$ dengan jarak kehamilan $\leq 2$ tahun.

Tabel 5. Distribusi Frekuensi Kejadian Baby Blues Syndrome BerdasarkanPendidikan

\begin{tabular}{|c|c|c|c|c|}
\hline Pendidikan & Normal & $\begin{array}{c}\text { Baby } \\
\text { Blues } \\
\text { Syndrome }\end{array}$ & Jumlah & $\begin{array}{c}\text { Presentase } \\
(\%)\end{array}$ \\
\hline Pendidikan Tinggi & 21 & 0 & 21 & 27,3 \\
\hline Pendidikan Rendah & 33 & 23 & 56 & 72,7 \\
\hline Total & 54 & 23 & 77 & 100 \\
\hline 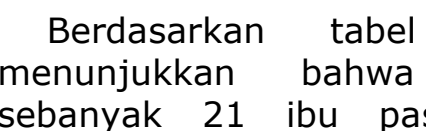 & $\begin{array}{l}5 \text { diatas } \\
\text { didapatkan } \\
\text { melahirkan }\end{array}$ & \multicolumn{3}{|c|}{$\begin{array}{l}\text { tinggi dan } 56 \text { ibu pascamelahirkan } \\
(72,7 \%) \text { dengan kategori pendidikan } \\
\text { rendah. }\end{array}$} \\
\hline
\end{tabular}
$(27,3 \%)$ dengan kategori pendidikan 
Tabel 6. Distribusi Frekuensi Kejadian Baby Blues Syndrome Berdasarkan Pekerjaan

\begin{tabular}{ccccc}
\hline Pekerjaan & Normal & $\begin{array}{c}\text { Baby Blues } \\
\text { Syndrome }\end{array}$ & Jumlah & Presentase (\%) \\
\hline Bekerja & 13 & 4 & 17 & 22,1 \\
Tidak Bekerja & 41 & 19 & 60 & 77,9 \\
\hline Total & $\mathbf{5 4}$ & $\mathbf{2 3}$ & $\mathbf{7 7}$ & $\mathbf{1 0 0}$ \\
\hline
\end{tabular}

Berdasarkan tabel 6 diatas

syndrome kategori bekerja dan sebanyak 60 ibu pascamelahirkan $(77,9 \%)$ dengan kejadian baby blues syndrome kategori tidak bekerja.

sebanyak 17 ibu pascamelahirkan $(22,1 \%)$ dengan kejadian baby blues

Tabel 7. Distribusi Frekuensi Kejadian Baby Blues Syndrome Berdasarkan Penghasilan

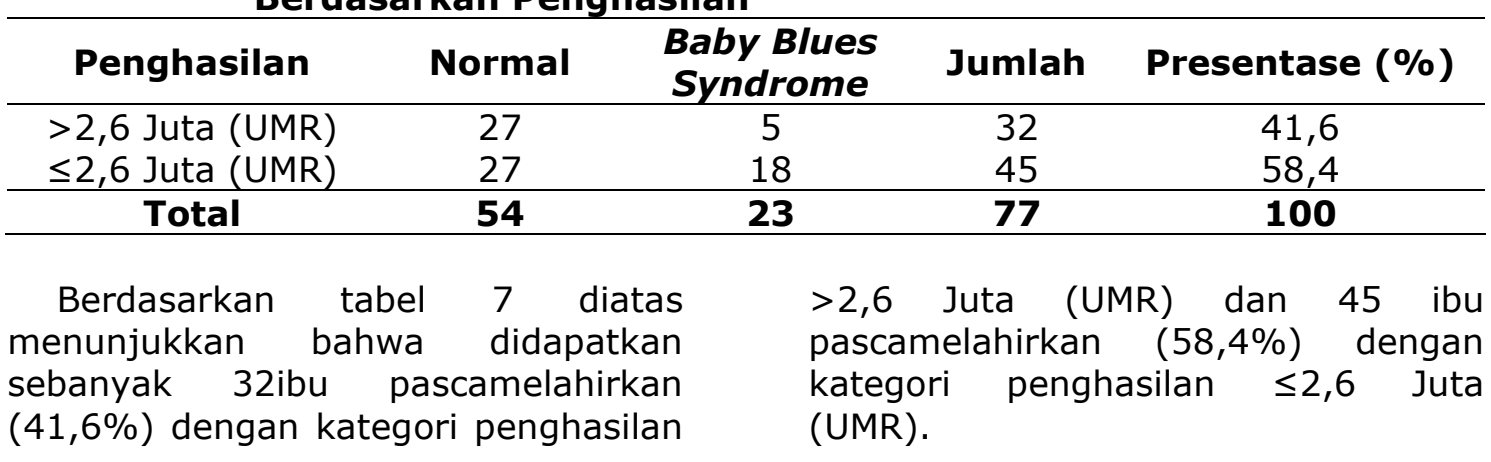

Tabel 8. Hasil Nilai Kuesioner

\begin{tabular}{|c|c|c|c|c|c|c|}
\hline \multirow{2}{*}{$\begin{array}{c}\text { Pertanyaan } \\
\text { Kuesioner }\end{array}$} & \multicolumn{4}{|c|}{ Nilai Kuesioner } & \multirow[b]{2}{*}{ Jumlah } & \multirow{2}{*}{$\begin{array}{c}\text { Presentase } \\
(\%)\end{array}$} \\
\hline & $\mathbf{0}$ & 1 & 2 & 3 & & \\
\hline 1. & 48 & 28 & 1 & 0 & 77 & 100 \\
\hline 2. & 50 & 26 & 1 & 0 & 77 & 100 \\
\hline 3. & 14 & 41 & 21 & 1 & 77 & 100 \\
\hline 4. & 28 & 28 & 21 & 0 & 77 & 100 \\
\hline 5. & 21 & 43 & 12 & 1 & 77 & 100 \\
\hline 6. & 10 & 52 & 15 & 0 & 77 & 100 \\
\hline 7. & 14 & 43 & 19 & 1 & 77 & 100 \\
\hline 8. & 38 & 37 & 2 & 0 & 77 & 100 \\
\hline 9. & 28 & 48 & 1 & 0 & 77 & 100 \\
\hline 10. & 64 & 10 & 3 & 0 & 77 & 100 \\
\hline Total & 315 & 356 & 96 & 3 & 770 & 1000 \\
\hline \multicolumn{4}{|c|}{$\begin{array}{l}\text { Berdasarkan tabel } 8 \text { diatas } \\
\text { menunjukkan terdapat } 10 \text { pertanyaan } \\
\text { dengan pilihan jawaban dari masing- } \\
\text { masing pertanyaan. Pertanyaan } 1,2 \text {, } \\
\text { dan } 4 \text { mendapatkan nilai } 0,1,2 \text {, atau } \\
3 \text { dengan kotak paling atas }\end{array}$} & \multicolumn{3}{|c|}{$\begin{array}{l}\text { bawah mendapatkan nilai } 3 \text {. } \\
\text { Pertanyaan } 3,5 \text { sampai dengan } 10 \\
\text { merupakan penilaian terbalik, dengan } \\
\text { kotak paling atas mendapatkan nilai } 3 \\
\text { dan kotak paling bawah mendapatkan } \\
\text { nilai } 0 .\end{array}$} \\
\hline
\end{tabular}
mendapatkan nilai 0 dan kotak paling 
Tabel 9. Hubungan Tingkat Usia Ibu Baby Blues Syndrome dan Tidak Baby Blues Syndrome

\begin{tabular}{|c|c|c|c|c|c|c|c|c|}
\hline \multirow{3}{*}{ Usia } & \multicolumn{4}{|c|}{ Baby Blues Syndrome } & \multirow{2}{*}{\multicolumn{2}{|c|}{ Jumlah }} & \multirow{2}{*}{\multicolumn{2}{|c|}{ Nilai }} \\
\hline & \multicolumn{2}{|c|}{$\mathbf{Y a}$} & \multicolumn{2}{|c|}{ Tidak } & & & & \\
\hline & $\mathbf{n}$ & $\%$ & $\mathbf{n}$ & $\%$ & $\mathbf{n}$ & $\%$ & $\mathbf{p}$ & $\begin{array}{c}\text { OR } \\
\text { (CI } 95 \%)\end{array}$ \\
\hline \multirow{2}{*}{$\begin{aligned} & 21-35 \\
& \text { Tahun } \\
\leq & 20 \text { dan } \\
> & 35 \text { Tahun }\end{aligned}$} & 17 & 22,1 & 42 & 54,5 & 59 & 76,6 & \multirow{3}{*}{0,942} & \multirow{3}{*}{$\begin{array}{c}1,235 \\
(0,399-3,826)\end{array}$} \\
\hline & 6 & 7,8 & 12 & 15,6 & 18 & 23,4 & & \\
\hline Total & 23 & 29,9 & 54 & 70,1 & 77 & 100 & & \\
\hline
\end{tabular}

Berdasarkan tabel 9 diatas menunjukkan hasil uji statistik diperoleh nilai $p=0,942$ yang berarti $\mathrm{p}>\mathrm{a}=0,05$ maka dapat disimpulkan

bahwa tidak ada hubungan antara usia dengan kejadian baby blues syndrome.

Tabel 10. Hubungan Paritas Ibu Baby Blues Syndrome dan Tidak Baby Blues Syndrome

\begin{tabular}{|c|c|c|c|c|c|c|c|c|}
\hline \multirow{3}{*}{ Paritas } & \multicolumn{4}{|c|}{ Baby Blues Syndrome } & \multirow{2}{*}{\multicolumn{2}{|c|}{ Jumlah }} & \multirow{2}{*}{\multicolumn{2}{|c|}{ Nilai }} \\
\hline & \multicolumn{2}{|c|}{$\mathbf{Y a}$} & \multicolumn{2}{|c|}{ Tidak } & & & & \\
\hline & $\mathbf{n}$ & $\%$ & $\mathbf{n}$ & $\%$ & $\mathbf{n}$ & $\%$ & $\mathbf{p}$ & $\begin{array}{c}\text { OR } \\
\text { (CI } 95 \%)\end{array}$ \\
\hline Primipara & 10 & 13,0 & 18 & 23,4 & 28 & 36,4 & \multirow{3}{*}{0,556} & \multirow{3}{*}{$\begin{array}{c}0,650 \\
(0,239-1,767)\end{array}$} \\
\hline Multipara & 13 & 16,9 & 36 & 46,8 & 49 & 63,6 & & \\
\hline Total & 23 & 29,9 & 54 & 70,1 & 77 & 100 & & \\
\hline
\end{tabular}

Berdasarkan tabel 10 diatas menunjukkan hasil uji statistik diperoleh nilai $p=0,556$ yang berarti bahwa tidak ada hubungan antara gravida dengan kejadian baby blues $\mathrm{p}>\mathrm{a}=0,05$ maka dapat disimpulkan syndrome.

Tabel 11. Hubungan Jarak Kehamilan Ibu Baby Blues Syndrome dan Tidak Baby Blues Syndrome

\begin{tabular}{|c|c|c|c|c|c|c|c|c|}
\hline \multirow{3}{*}{$\begin{array}{c}\text { Jarak } \\
\text { Kehamilan }\end{array}$} & \multicolumn{4}{|c|}{ Baby Blues Syndrome } & \multirow{2}{*}{\multicolumn{2}{|c|}{ Jumlah }} & \multirow{2}{*}{\multicolumn{2}{|c|}{ Nilai }} \\
\hline & \multicolumn{2}{|c|}{$\mathbf{Y a}$} & \multicolumn{2}{|c|}{ Tidak } & & & & \\
\hline & $\mathbf{n}$ & $\%$ & $\mathbf{n}$ & $\%$ & $\mathbf{n}$ & $\%$ & $\mathbf{p}$ & $\begin{array}{c}\text { OR } \\
\text { (CI 95\%) }\end{array}$ \\
\hline$>2$ Tahun & 2 & 2,6 & 24 & 31,2 & 26 & 33,8 & 0.006 & 8,400 \\
\hline$\leq 2$ Tahun & 21 & 27,3 & 30 & 39,0 & 51 & 66,2 & & $(1,789-39,439)$ \\
\hline Total & 23 & 29,9 & 54 & 70,1 & 77 & 100 & & \\
\hline
\end{tabular}

Berdasarkan tabel 11 diatas menunjukkan hasil uji statistik diperoleh nilai $p=0,006$ yang berarti $\mathrm{p} \leq \mathrm{a}=0,05$ maka dapat disimpulkan

bahwa terdapat hubungan antara jarak kehamilan dengan kejadian baby blues syndrome. 
Tabel 12. Hubungan Pendidikan Ibu Baby Blues Syndrome dan Tidak Baby Blues Syndrome

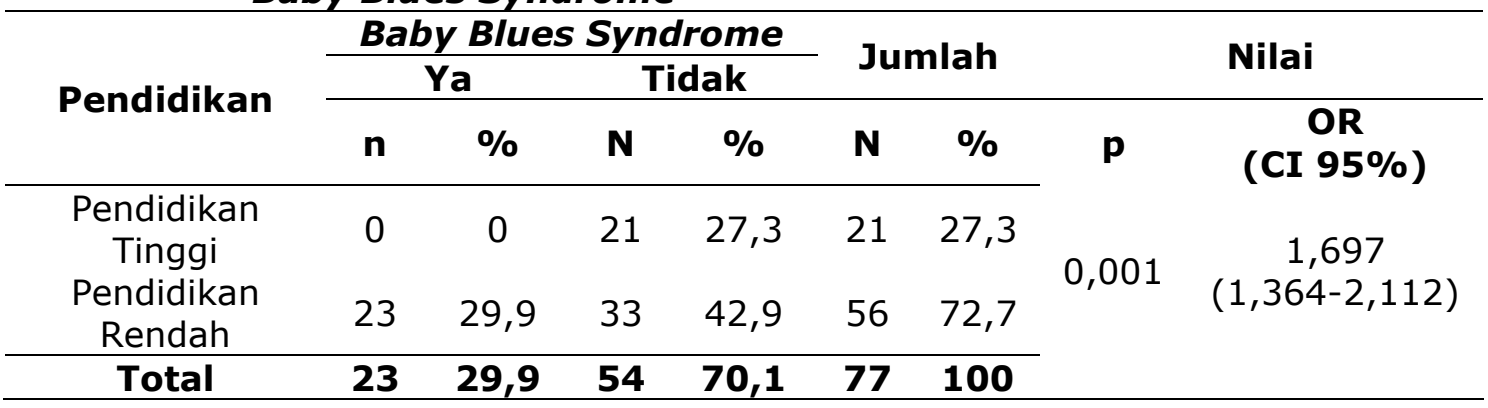

Berdasarkan tabel 12 diatas menunjukkan hasil uji statistik diperoleh nilai $p=0,001$ yang berarti $\mathrm{p} \leq \mathrm{a}=0,05$ maka dapat disimpulkan

bahwa terdapat hubungan antara pendidikan dengan kejadian baby blues syndrome.

Tabel 13. Hubungan Pekerjaan Ibu Baby Blues Syndrome dan Tidak Baby Blues Syndrome

\begin{tabular}{|c|c|c|c|c|c|c|c|c|}
\hline \multirow{3}{*}{ Pekerjaan } & \multicolumn{4}{|c|}{ Baby Blues Syndrome } & \multirow{2}{*}{\multicolumn{2}{|c|}{ Jumlah }} & \multirow{2}{*}{\multicolumn{2}{|c|}{ Nilai }} \\
\hline & \multicolumn{2}{|c|}{ Ya } & \multicolumn{2}{|c|}{ Tidak } & & & & \\
\hline & $\mathbf{n}$ & $\%$ & $\mathbf{n}$ & $\%$ & $\mathbf{n}$ & $\%$ & $\mathbf{p}$ & $\begin{array}{c}\text { OR } \\
\text { (CI 95\%) }\end{array}$ \\
\hline \multirow{2}{*}{$\begin{array}{c}\text { Bekerja } \\
\text { Tidak } \\
\text { Bekerja }\end{array}$} & 4 & 5,2 & 13 & 16,9 & 17 & 22,1 & \multirow{3}{*}{0,729} & \multirow{3}{*}{$\begin{array}{c}1,506 \\
(0,433-5,234)\end{array}$} \\
\hline & 19 & 24,7 & 41 & 53,2 & 60 & 77,9 & & \\
\hline Total & 23 & 29,9 & 54 & 70,1 & 77 & 100 & & \\
\hline
\end{tabular}

Berdasarkan tabel 13 diatas menunjukkan hasil uji statistik diperoleh nilai $p=0,729$ yang berarti $\mathrm{p}>\mathrm{a}=0,05$ maka dapat disimpulkan bahwa tidak ada hubungan antara pekerjaan dengan kejadian baby blues syndrome.

Tabel 14. Hubungan Penghasilan Ibu Baby Blues Syndrome dan Tidak Baby Blues Syndrome

\begin{tabular}{|c|c|c|c|c|c|c|c|c|}
\hline \multirow{3}{*}{ Penghasilan } & \multicolumn{4}{|c|}{ Baby Blues Syndrome } & \multirow{2}{*}{\multicolumn{2}{|c|}{ Jumlah }} & \multirow{2}{*}{\multicolumn{2}{|c|}{ Nilai }} \\
\hline & \multicolumn{2}{|c|}{$\mathbf{Y a}$} & \multicolumn{2}{|c|}{ Tidak } & & & & \\
\hline & $\mathbf{n}$ & $\%$ & $\mathbf{N}$ & $\%$ & $\mathbf{N}$ & $\%$ & $\mathbf{P}$ & $\begin{array}{c}\text { OR } \\
\text { (CI 95\%) }\end{array}$ \\
\hline \multirow{2}{*}{$\begin{array}{l}>2,6 \text { Juta } \\
\text { (UMR) } \\
\leq 2,6 \text { Juta } \\
\text { (UMR) }\end{array}$} & 5 & 6,5 & 27 & 35,1 & 32 & 41,6 & \multirow{3}{*}{0,040} & \multirow{3}{*}{$\begin{array}{r}3,600 \\
(1,168- \\
11,092)\end{array}$} \\
\hline & 18 & 23,4 & 27 & 35,1 & 45 & 58,4 & & \\
\hline Total & 23 & 29,9 & 54 & 70,1 & 77 & 100 & & \\
\hline
\end{tabular}

Berdasarkan tabel 14 diatas menunjukkan hasil uji statistik diperoleh nilai $p=0,040$ yang berarti $\mathrm{p} \leq \mathrm{a}=0,05$ maka dapat disimpulkan

\section{PEMBAHASAN}

Menurut hasil penelitian pada ibu pascamelahirkan di Praktik Mandiri Bidan Wilayah Kecamatan Rajabasa bahwa tidak ada hubungan antara penghasilan dengan kejadian baby blues syndrome.

Bandar Lampung Tahun 2019, didapatkan distribusi frekuensi ibu pascamelahirkan dengan kejadian baby blues syndrome berjumlah 77 
ibu pascamelahirkan. Responden didapatkan didapatkan 54 ibu pascamelahirkan $(70,1 \%)$ normal dan 23 ibu pascamelahirkan (29,9\%) dengan kejadian baby blues syndrome.

Didapatkan hasil tertinggi yaitu ibu pascamelahirkan normal dengan 54 responden artinya $70,1 \%$ ibu pascammelahirkan pada penelitian ini bisa beradaptasi dengan perubahan yang terjadi setelah melahirkan.

Ditinjau dari hasil analisis, usia ibu tidak memiliki makna secara statistik karena memiliki nilai $p>0,05$ $(p=0,942)$, sehingga tidak terdapat hubungan antara usia dengan kejadian baby blues syndrome. Hasil penelitian ini dapat dipengaruhi oleh faktor lain seperti yang terdapat pada penelitian yang dilakukan oleh Fatmawati (2015) yaitu faktor dukungan sosial suami. Menurut Noor (2000) usia merupakan salah satu sifat karakteristik tentang orang yang sangat utama. Usia mempunyai hubungan dengan tingkat keterpaparan, besarnya risiko serta sifat resistensi. Perbedaan pengalaman terhadap masalah kesehatan atau penyakit dan pengambilan keputusan dipengaruhi usia individu tersebut. Mayoritas responden pada penelitian ini usia $\leq 35$ tahun sebanyak 59 ibu pascamelahirkan $(76,6 \%)$, sehingga dapat disimpulkan mayoritas responden berada dalam kategori aman untuk hamil dan persalinan ini sesuai dengan pendapat dari Prawiroharjo (2014) yaitu usia ibu yang aman untuk kehamilan dan dilakukan persalinan adalah ibu yang berusia $>20$ tahun karena dianggap telah memiliki kesiapan baik secara fisik, emosi, psikologi, sosial, maupun ekonomi. ibu yang hamil di usia $\leq 20$ tahun memiliki organ reproduksi yang belum matang sempurna sehingga mengakibatkan ketakutan dalam persalinan dan untuk ibu yang hamil pada usia > 35 tahun akan mengalami kecemasan terhadap kehamilan dan persalinan serta fungsi organ reproduksi yang menurun seiring bertambahnya usia.

Berdasarkan tabel3 diatas menunjukkan bahwa menunjukan ibu primipara yang mengalami baby blues syndrome sebanyak 10 responden $(13 \%)$ dan ibu multipara yang mengalami baby blues syndrome sebanyak 13 responden (16,9\%). Ditinjau dari hasil analisis, paritas ibu tidak memiliki makna secara statistik karena nilai $p>0,05 \quad(p=0,556)$, sehingga tidak terdapat hubungan antara gravida dengan kejadian baby blues syndrome. Hasil penelitian ini dapat dipengaruhi oleh faktor lain seperti kehamilan yang tidak direncanakan seperti pendapat dari Elvira (2006) pada perempuan yang hamil tidak direncanakan misalnya karena belum menikah atau pada ibu yang sudah tidak menginginkan anak lagi, kejadian depresi postpartum lebih tinggi dibandingkan dengan perempuan yang siap dan sangat menantikan kelahiran bayinya. Hubungan gravida dengan baby blues synrome masih diperdebatkan dimana sebagian penelitian juga melaporkan wanita multipara lebih mudah terkena baby blues syndrome (Davidson, 1972).Sedangkan beberapa peneliti tidak menemukan adanya hubungan antara postpartum blues dan paritas (Pitt, 1973; Ballinger et al., 1979; Stein, 1980; Hapgood et al., 1988 dalam Seyfreid \& Marcus, 2003).

Berdasarkan tabel4 diatas menunjukkan ibu yang mengalami baby blues syndrome sebanyak 23 ibu pascamelahirkan dengan distribusi terbanyak 21 ibu pascamelahirkan $(27,3 \%)$ jarak kehamilan $\leq 2$ tahun atau lebih banyak ibu yang pertama kali mengalami persalinan (primipara). Secara statistik pada penelitian ini didapatkan nilai $\mathrm{p} \leq 0.05$ $(p=0,006)$, sehingga terdapat hubungan antara jarak kehamilan dengan kejadian baby blues syndrome. Dengan risiko ibu dengan jarak kehamilan $\leq 2$ tahun berisiko 8,4 kali lipat lebih besar terkena baby blues syndrome daripada ibu dengan 
jarak kehamilan $>2$ tahun. Hal ini diperkuat oleh beberapa studi yang menunjukkan wanita primipara mempunyai risiko lebih besar terhadap baby blues syndrome(Yalom et al., 1968; Nott et al.,1976; Gard et al., 1986 dalam Wijayanti, 2013). Sejalan dengan studi diatas, Machmudah (2010) menyatakan bahwa ibu yang sudah pernah melahirkan dan berpengalaman dalam merawat bayinya dibandingkan primipara, primipara akan cenderung mengalami gangguan mood ringan postpartum. Sehingga Machmudah (2010) menyimpulkan dalam penelitiannya bahwa terdapat pengaruh antara paritas dengan kemungkinan terjadinya baby blues syndrome.

Berdasarkan tabel 5 diatas menunjukkan sebanyak 21 ibu pascamelahirkan $(27,3 \%)$ dengan kejadian baby blues syndrome kategori pendidikan tinggi dan 56 ibu pascamelahirkan $(72,7 \%)$ dengan kejadian baby blues syndrome kategori pendidikan rendah. Sesuai dengan pendapat Wawan (2010), pengetahuan sangat erat hubungannya dengan pendidikan, dimana diharapkan bahwa dengan pendidikan yang tinggi maka orang tersebut akan semakin luas pengetahuannya, bukan berarti seseorang pendidikan rendah mutlak berpengetahuan rendah juga. Menurut Gurel (2000) ada hubungan antara jumlah dan riwayat kelahiran dengan tingkat pendidikan. Ibu yang tingkat pendidikannya rendah akan mempunyai jumlah anak yang banyak dan kualitas dalam perawatan bayi juga tidak baik. Kehamilan yang terjadi pada usia muda, biasanya terjadi pada perempuan yang putus sekolah. Hal ini menunjukkan bahwa pendidikan mempengaruhi pengetahuan ibu dalam banyaknya anak, jarak anak, serta proses mengahadapi stressor yang akan terjadi. Secara statistik pada penelitian ini didapatkan nilai $p \leq 0,05$ $(p=0,001)$, Sehingga terdapat hubungan antara pendidikan dengan kejadian baby blues syndrome. Dengan risiko ibu dengan pendidikan rendah berisiko 1,697 kali lipat lebih besar terkena baby blues syndrome daripada ibu dengan pendidikan tinggi.

Ditinjau dari hasil analisis, pekerjaan ibu tidak memiliki makna secara statistik karena nilai $p>0,05$ $(p=0,729)$, sehingga tidak terdapat hubungan antara pekerjaan dengan kejadian baby blues syndrome. Berdasarkan tabel 6 diatas menunjukkan bahwa didapatkan sebanyak 17 ibu pascamelahirkan $(22,1 \%)$ dengan kejadian baby blues syndrome kategori bekerja dan sebanyak 60 ibu pascamelahirkan $(77,9 \%)$ dengan kejadian baby blues syndrome kategori tidak bekerja.Pekerjaan mempengaruhi kehidupan sehari-hari ibu, apalagi bila ibu tidak bekerja dan memiliki pengeluaran yang sangat besar. Sesuai dengan pendapat Bobak (2005) status sosial ekonomi merupakan salah satu faktor pendukung terjadinya baby blues syndrome, terkait dengan pemenuhan kebutuhan dan perawatan pada bayi. Baby blues syndrome banyak terjadi pada ibu yang tidak mempunyai penghasilan atau tidak bekerja atau pada ibu yang bekerja dan mempunyai penghasilan kurang dari satu juta rupiah (Curry, 2008).

Berdasarkan tabel 7 diatas menunjukkan sebanyak 32 ibu pascamelahirkan $(41,6 \%)$ dengan kejadian baby blues syndrome kategori penghasilan $>2,6$ Juta (UMR) dan 45 ibu pascamelahirkan $(58,4 \%)$ dengan kejadian baby blues syndrome kategori penghasilan $\leq 2,6$ Juta (UMR). Sesuai dengan pendapat Curry (2008) baby blues syndrome banyak terjadi pada ibu yang tidak mempunyai penghasilan atau tidak bekerja atau pada ibu yang bekerja dan mempunyai penghasilan kurang dari satu juta rupiah. Secara statistik pada penelitian ini didapatkan nilai $p \leq 0,05(p=0,040)$, Sehingga terdapat hubungan antara penghasilan dengan kejadian baby blues syndrome. 
Sehingga ibu dengan penghasilan $\leq$ 2,6 Juta (UMR) perbulan berisiko 3,6 kali lipat lebih besar terkena baby blues syndrome daripada ibu yang penghasilan $>2,6$ Juta (UMR) perbulan.

Berdasarkan tabel 8 diatas menunjukkan pertanyaan paling banyak dijawab adalah pertanyaan nomor 10 yaitu "muncul pikiran untuk menyakiti diri sendiri" dengan jawaban terbanyak bernilai 0 "tidak pernah sama sekali" sebanyak 64 responden, artinya sebanyak 64 ibu menyatakan "ibu tidak pernah sama sekali muncul pikiran untuk menyakiti diri sendiri". Pertanyaan kedua yang terbanyak adalah pertanyaan nomor 6 yaitu "saya merasa kewalahan dalam mengerjakan segala sesuatu" dengan jawaban terbanyak bernilai 1 "tidak terlalu, saya mampu mengerjakan segala sesuatu dengan baik" sebanyak 52 responden, artinya sebanyak 52 ibu menyatakan "ibu tidak terlalu merasa kewalahan dalam mengerjakan segala sesuatu, ibu mampu mengerjakan segala sesuatu dengan baik". Pertanyaan ketiga yang terbanyak adalah pertanyaan nomor 2 yaitu " saya mampu menikmati setiap hal yang telah saya lakukan" dengan jawaban terbanyak bernilai 0 "selalu" sebanyak 50 responden, artinya sebanyak 50 ibu menyatakan "ibu selalu mampu menikmati setiap hal yang telah ibu lakukan.

\section{KESIMPULAN}

\begin{tabular}{lrr}
\multicolumn{1}{c}{ Berdasarkan hasil } & penelitian \\
distribusi & frekuensi & ibu \\
pascamelahirkan & dengan & kejadian
\end{tabular} baby blues syndrome di Praktik Mandiri Bidan Wilayah Kecamatan Rajabasa Bandar Lampung Tahun 2019, maka dapat disimpulkan bahwa:

1. Distribusi frekuensi ibu pascamelahirkan berjumlah 77 . Responden didapatkan 54 ibu pascamelahirkan $(70,1 \%)$ normal atau tidak mengalami baby blues syndrome dan 23 ibu pascamelahirkan $(29,9 \%)$ dengan kejadian baby blues syndrome.
2. Tingkat kecenderungan kejadian baby blues syndrome mengarah ke depresi menurut penilaian kuesioner EPDS sebanyak 29,9\% (23 ibu pascamelahirkan).

3. Terdapat faktor yang berpengaruh terhadap terjadinya baby blues syndrome, seperti jarak kehamilan $\leq 2$ tahun, pendidikan ibu yang rendah, dan penghasilan $\leq 2,6$ juta (UMR) sehingga tidak mencukupi kebutuhan ibu dan bayi.

4. Untuk gejala baby blues syndrome dari pengisian kuesioner EPDS yaitu ibu terkadang menyalahkan dirinya sendiri saat sesuatu tidak terjadi sebagaimana mestinya, terkadang ibu merasa cemas atau khawatir tanpa alasan yang jelas, dan terkadang ibu merasa tidak bahagia sehingga mengalami kesulitan tidur.

\section{SARAN}

1. Diharapkan sebelum ibu melahirkan mempersiapkan persiapan yang harus dilakukan untuk melahirkan dengan baik. Setelahnya ibu dapat memahami dan menerima perubahan yang terjadi setelah melahirkan, penerimaan diharapkan agar ibu tidak terlalu stress terhadap perubahan yang terjadi.

2. Bagi peneliti selanjutnya, semoga penelitian ini dapat menjadi bahan informasi dan evidance base dan pertimbangan bagi yang berkepentingan untuk melakukan penelitian sejenis.

3. Diharapkan melakukan langkahlangkah pencegahan kepada ibu yang akan melahirkan dan setelah melahirkan: Melakukan skrining prenatal (ANC), Memberikaan penjelasan kepadaibu mengenai kehamilan dan kemungkinan timbulnya baby blues syndrome, menyediakan forum atau grup bagi ibu hamil dan setelah melahirkan agar ibu bisa saling bertukar informasi 
mengenai kehamilan dan wadah untuk bertukar cerita.

4. Bagi pihak universitas, penelitian ini diharapkan menjadi sumber data dasar dan referensi yang digunakan peneliti selanjutnya, khususnya mengenai kejadian baby blues syndrome pada ibu pascamelahirkan.

\section{UCAPAN TERIMAKASIH}

Bidan praktik mandiri yang telah memberikan izin dan membantu dalam penelitian, serta semua pihak yang telah terlibat dalam penelitian ini yang tidak bisa disebutkan satu persatu, saya ucapkan terimakasih.

\section{DAFTAR PUSTAKA}

Ballinger, C. B., Buckley, D. E., Naylor, G. J., \& Stansfield, D. A. (1979). Emotional disturbance following childbirth: clinical findings and urinary excretion of cyclic AMP (adenosine 3'5'cyclic monophosphate). Psychological Medicine, 9(2), 293-300.

Bobak, I. M., Lowdermilk, D. L., Jensen, M. D., \& Perry, S. E. (2005).Buku ajar keperawatan maternitas.Jakarta: EGC.

Curry, A. F., Menezes, P. R., Tedesco, J. J. A., \& Kahalle, S. (2008). Maternity "blues": prevalence and risk factors. Spanish Journal of Psychology, 11(2), 593-599.

Davidson, J. R. T. (1972). Postpartum mood change in Jamaican women: a description and discussion on its significance. The British Journal of Psychiatry, 121(565), 659663.

Elvira SD. (2006). Depresi Pasca Persalinan. Jakarta: Balai penerbit FKUI. 1-43

Fatmawati, D. A. (2015). Faktor risiko yang berpengaruh terhadap kejadian postpartum blues.Eduhealth, 5(2).

Gard, P. R., Handley, S. L., Parsons, A. D., \& Waldron, G. (1986). A multivariate investigation of postpartum mood
disturbance.The British Journal of Psychiatry, 148(5), 567-575.

Gürel, S. A., \& Gürel, H. (2000). The evaluation of determinants of early postpartum low mood: the importance of parity and interpregnancy interval. European Journal of Obstetrics \& Gynecology and Reproductive Biology, 91(1), 21-24.

Hapgood, C. C., Elkind, G. S., \& Wright, J. J. (1988). Maternity blues: phenomena and relationship to later post partum depression. Australian and New Zealand Journal of Psychiatry, 22(3), 299-306.

Jhaquin, A. (2010). Psikologi untuk kebidanan.Yogyakarta: Nuha Medika.

Lynn CE, Pierre, C. M. S. (2007). The taboo of motherhood: postpartum depression. International Journal of Human Caring, 11(2), 22-31.

Machmudah, T. (2010).Pengaruh persalinan dengan komplikasi terhadap kemungkinan terjadinya Postpartum Blues di Kota Semarang [Tesis]. Jakarta: Universitas Indonesia.

Munawaroh.(2008). Faktor-faktor yang Berhubungan dengan Postpartum Blues pada Ibu Pascapersalinan di Wilayah Kerja Puskesmas Kajhu Kecamatan Baitussalam Kabupaten Aceh Besar. Surakarta: Universitas Muhammadiyah Surakarta

Noor.(2000). Dasar Epidemiologi. Jakarta: Rineka Cipta

Nott, P. N., Franklin, M., Armitage, C., \& Gelder, M. G. (1976).Hormonal changes and mood in the puerperium. The British Journal of Psychiatry, 128(4), 379-383.

Pilliteri, A. (2003). Maternal and child health nursing.Philadelphia: Lippincott.

Pitt, B. (1973). Maternity blues. The British journal of psychiatry, 122(569), 431-433.

Prawirohardjo, S. (2014).IImu Kebidanan. Jakarta: Yayasan 
Bina Pustaka Sarwono Prawirohardjo

Seyfried, L. S., \& Marcus, S. M. (2003).Postpartum mood disorders.International Review of Psychiatry, 15(3), 231-242.

Suryani, E \& Widyaningsih, $\mathrm{H}$. (2010).Psikologi Ibu dan Anak. Yogyakarta: Fitramaya

Stein, L. I., \& Test, M. A. (1980). Alternative to mental hospital treatment: I. Conceptual model, treatment program, and clinical evaluation. Archives of general psychiatry, 37(4), 392-397.

Wawan, A., \& Dewi, M. (2010).Teori dan pengukuran pengetahuan, sikap dan perilaku manusia.Yogyakarta: Nuha Medika.

Wijayanti, K., Wijayanti, F. A., \& Nuryanti, E. (2013). Gambaran faktor-faktor risiko postpartum blues di wilayah kerja puskesmas blora. Jurnal Kebidanan, 2(5), 57-64.

Yalom, I. D., Lunde, D. T., Moos, R. H., \& Hamburg, D. A. (1968). Postpartum blues syndrome: A description and related variables. Archives of General Psychiatry, 18(1), 16-27. 